Elsevier

GENE 1439

\title{
Methylation of plasmacytoma c-myc genes
}

(Recombinant DNA; chromosomal translocation; gene regulation; kidney; liver; DNA sequence)

\author{
Wesley Dunnick*, James Baumgartner, Lee Fradkin, Cynthia Schultz and Paul Szurek \\ Department of Microbiology and Immunology, The University of Michigan Medical School, Ann Arbor, MI 48109 (U.S.A.) \\ Tel. (313)763-3195
}

(Received April 19th, 1985)

(Revision received August 2nd, 1985)

(Accepted August 12th, 1985)

\section{SUMMARY}

The chromosomal translocation associated with many tumors of immunoglobulin-producing cells frequently results in the joining of the immunoglobulin heavy-chain locus and the c-myc oncogene. This translocation of c-myc has profound structural and functional consequences for the oncogene, including loss of the $5^{\prime}$ end of the gene and transcriptional deregulation. We report in this communication that translocation results in a new methylation pattern of c-myc. In normal kidney and liver tissue, the c-myc gene is methylated at its $3^{\prime}$ end. The translocated gene in plasmacytoma DNA is extensively demethylated. On the other hand, the nonrearranged c-myc gene in plasmacytoma DNA (which is transcriptionally silent) is extensively methylated. In addition, we confirm the nucleotide sequence (with 19 discrepancies out of $1400 \mathrm{bp}$ ) $5^{\prime}$ to the murine c-myc gene, as reported by Corcoran et al. [Cell 40 (1985) 71-79].

\section{INTRODUCTION}

The characteristic chromosomal translocation found in many $B$ cell tumors results in the joining of a c-myc oncogene (from murine chromosome 15) to the immunoglobulin heavy-chain locus (chromosome 12: Klein, 1983; Perry, 1983; Robertson, 1983). As a result of the reciprocal translocation process, the $5^{\prime}$ end of the c-myc gene is separated

* To whom correspondence and reprint requests should be addressed.

Abbreviations: bp, base pair(s); kb, 1000 bp; NIARD, see Fig. 2 and section c; SDS, sodium dodecyl sulfate; SSC, $0.15 \mathrm{M} \mathrm{NaCl}$, $0.015 \mathrm{M} \mathrm{Na}_{3} \cdot$ citrate, pH 7-8. from the bulk of the gene. DNA from plasmacytoma cells have parts of the c-myc gene in three different locations: a nonrearranged version of the gene on a normal chromosome 15; the bulk of the gene, including all of the protein-coding potential, associated with the part of immunoglobulin heavy-chain locus on a 12:15 translocation chromosome; and the $5^{\prime}$ end of the c-myc gene associated with the $5^{\prime}$ end of the heavy-chain locus on a 15:12 translocated chromosome (Cory et al., 1983). Translocation and truncation of c-myc are correlated with increased transcriptional activity of the translocated gene, but transcriptional silence of the normal c-myc gene (Perry, 1983; Robertson, 1983).

Eukaryotic genes that are transcriptionally active tend to be undermethylated, whereas those that are 
transcriptionally less active tend to be methylated (Razin and Riggs, 1980). Prevention of methylation by 5-azacytidine results in dramatic increases in transcriptional activity of some eukaryotic genes (Groudine et al., 1981; Compere and Palmiter, 1981). Finally, recombinant DNA molecules propagated in Escherichia coli, and therefore carrying all of their CpG dinucleotides in the demethylated form, are transcriptionally active when inserted into eukaryotic nuclei. On the other hand, the same recombinant DNA molecules, when methylated in vitro, are now inactive in eukaryotic nuclei (Fradin et al., 1982; Busslinger et al., 1983). We have studied the effect of c-myc translocation on gene structure by investigation of the methylation pattern of the c-myc gene from plasmacytoma cells and from normal (kidney and liver) cells.

\section{EXPERIMENTAL AND DISCUSSION}

\section{(a) Clones and methods}

The recombinant DNA molecule $\gamma$ M52 includes the translocated c-myc gene from the murine plasmacytoma P3. The recombinant DNA molecule $\mathrm{pX} 27-3$ includes the reciprocal product of the P3 translocation; that is, half of the first exon, and all of the 5 'flanking region. The derivation and structure of these clones have been described in detail elsewhere (Dunnick et al., 1983). The clone LF11 is a HindIII subclone in M13 of a 1.5-kb HindIII fragment that includes a large portion of 5 '-flanking sequences of the murine c-myc gene from the clone $\mathrm{pX} 27-3$, and ends at the HindIII site in the $5^{\prime}$-most exon (Fig. 1).

Methods for determining nucleotide sequences and for Southern hybridization analysis are described in the appropriate figure legends.

\section{(b) Sequence of c-myc 5' flanking region}

The sequence of $1400 \mathrm{bp}$ of murine c-myc 5' flanking region was determined. As this sequence has been published by Corcoran et al. (1985), we present here only the 19 discrepancies (see legend to Fig. 1). This sequence will serve as a database for at least two different lines of investigation. (i) It will aid in the exact location of $c-m y c$ translocation sites in

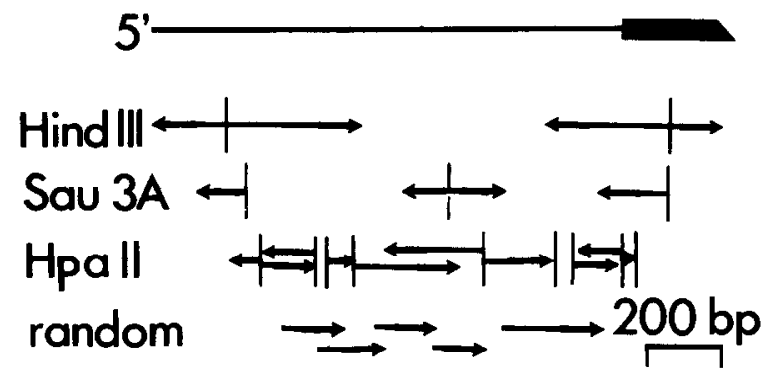

Fig. 1. Sequences in the murine c-myc oncogene. A schematic diagram of the $5^{\prime}$-flanking region and part of the first exon (darkened box) of the translocated c-myc gene in the murine plasmacytoma P3 is shown. The direction and extent of dideoxy sequences (Sanger et al., 1980), derived in bacteriophage M13 (Messing and Vieira, 1982) from HindIII, Sau3A or HpaII restriction fragments, or from random fragments generated by sonications are shown. Our sequence is exactly the same as that derived from the germline c-myc gene by Corcoran et al. (1985), with the following discrepancies (numbering according to Corcoran et al., 1985): delete T-1392; delete G-897; insert G after -890 ; insert $\mathrm{G}$ after -761 ; delete $\mathrm{G}-746$; substitute $\mathrm{G}$ for $\mathrm{C}-745$; delete G-743; delete T-536; delete C-405; delete A-357; insert C after -266 ; substitute $G$ for $A-190$; insert $G$ after -183 ; insert $C$ after -141 ; substitute G for A-109; delete A-100; insert two As after -95 ; substitute A for G-60; delete G-12.

the 5' end of the gene and the analysis of nucleotide sequences that might be important to the translocation process. (ii) It provides the sequence of the 5 ' end of the gene, a region that may play a key role in gene regulation (Perry, 1983; Robertson, 1983).

\section{(c) Methylation of CCGG sites}

We found a high concentration of HpaII sites (recognition sequence CCGG) in the $5^{\prime}$-flanking region of this gene. Because the $5^{\prime}$ end of the c-myc gene may be important to regulation of gene expression, and because it includes so many CCGG sequences, we were interested to determine the extent and pattern of methylation of c-myc genes with different structures in different tissues. Using $\mathrm{HpaII}$ cleavage, and the Southern (1975) hybridization technique, we examined the methylation state of c-myc in a mixture of kidney and liver DNA, and in P3 (a murine plasmacytoma cell line) DNA (Fig. 2). Of course, neither allele is rearranged in kidney and liver DNA; both c-myc genes are found in a $9.8-\mathrm{kb}$ KpnI fragment (lane 5). With the probe for the second exon, third exon, first intron, and second 


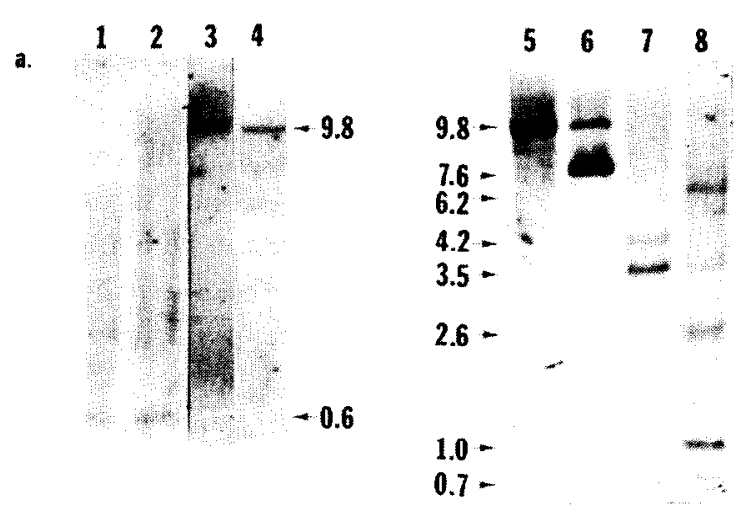

b.

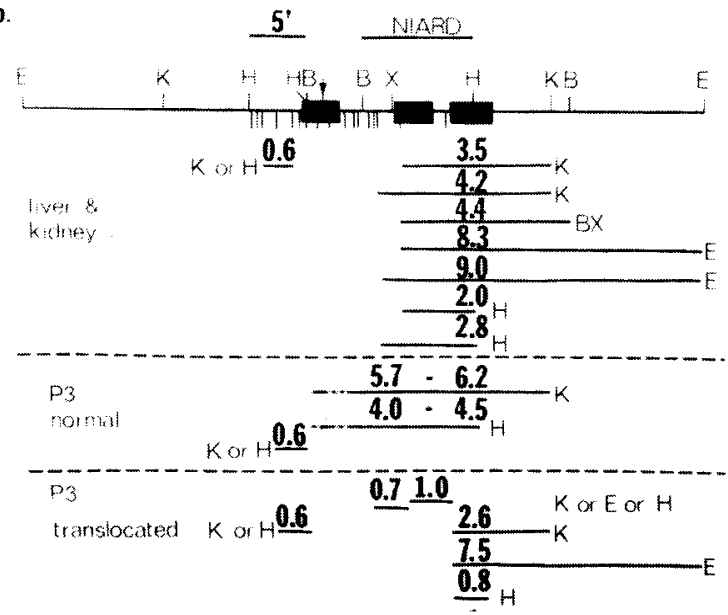

Fig. 2. Methylation of the c-myc oncogene. (a) High- $M_{\mathrm{r}}$ DNA from pooled kidneys and livers (lanes 2, 4, 5, and 7) or from plasmacytoma P3 (lanes 1, 3,6, and 8) was digested with $K p n I$ alone (lanes 3-6) or with $K p n I+H p a I I$ (lanes 1, 2, 7, and 8). The digested samples were fractionated on a $0.8 \%$ agarose gel and blotted onto nitrocellulose paper (Southern, 1975). Hybridization to nick-translated 5'-flanking region probe (LF11) (lanes 1-4) or the probe for the second exon, third exon, first intron, and second intron (NIARD; Harris et al., 1982; lanes 5-8) was in $6 \times \mathrm{SSC}$ at $68^{\circ} \mathrm{C}$. The sizes (in kb) of some DNA fragments are shown. (b) A restriction enzyme cleavage site map (with relevant sites only) for the murine c-myc gene. Vertical lines below the gene: known HpaII sites. HpaII sites in the $3^{\prime}$ end of the c-myc gene were determined by mapping of the c-myc molecular clone $\gamma \mathrm{M} 52$ (Dunnick et al., 1983). Black boxes: c-myc exons. The arrow above the first c-myc exon notes the translocation site in P3 DNA (Neuberger and Cabali, 1983; Dunnick et al., 1983). We have digested plasmacytoma P3 DNA and a mixture of murine kidney and liver DNA with $K p n I(K)$ alone, with $E c o$ RI (E) alone, with HindIII (H) alone, or with $B a m \mathrm{HI}+X b a \mathrm{I}(\mathrm{BX})$. After the primary digestion, each sample was digested with $\mathrm{HpaII}$ and subjected to Southern hybridization analysis. Some of the resulting autoradiographs are shown in Fig. 2a and 3b,c. Analysis of that set of data (including those not shown) allowed us to locate the various restriction fragments within the c-myc gene. The size and location of those fragments is shown. The enzyme used in the primary digestion, intron of c-myc (NIARD; Harris et al., 1982), we detected both the germline and translocated alleles (9.8- and 7.6-kb fragments; lane 6) in P3 DNA. (The greater hybridization signal associated with the translocated fragment is likely to reflect ploidy differcnces between the translocated and normal chromosomes.) KpnI + HpaII digestion of kidney and liver DNA, followed by Southern hybridization analysis with the NIARD probe, revealed three predominant fragments $(0.7,3.5$ and $4.2-\mathrm{kb}$, lane 7$)$. Primary digestion with EcoRI, BamHI $+X b a \mathrm{I}$, or HindIII instead of $K p n I$ allowed us to place these fragments at the $3^{\prime}$ end of the c-myc gene, suggesting complete methylation of the HpaII site in the second intron, and partial methylation of the site in the second exon. Similar experiments with plasmacytoma P3 DNA revealed a different pattern of methylation. In P3 DNA at least one allele is extensively undermethylated, yielding 2.6, 1.0, and $0.7-\mathrm{kb}$ fragments (lane 8). On the other hand, fragments equal to or larger than those observed in kidney and liver DNA were also detected $(3.5,6.2$, and $7.6 \mathrm{~kb})$.

\section{(d) Differential methylation of two plasmacytoma c-myc alleles}

To determine which allele in P3 DNA is methylated and which is demethylated, we fractionated the two alleles by centrifugation in a sucrose gradient. The normal allele is found in a $20-\mathrm{kb} E c o$ RI fragment (Harris et al., 1982; Cory et al., 1983), whereas the translocated allele is found in a 14-kb fragment (Cory et al., 1983; Dunnick et al., 1983). EcoRI-digested P3 genomic DNA was fractionated on a sucrose gradient, and fractions were pooled as described in Fig. 3a. These fractionated DNA samples were fur-

with HpaII being used in every case in the secondary digestion, is indicated by the appropriate abbreviation. For example, the 3.5-kb fragment resulting from primary digestion with $K p n I$ and sccondary digcstion with IIpaII, and detected by the NIARD probe [lane 7 , in (a)], is located in the second exon, second intron, and third exon of the kidney and liver gene. In those cases in which two or three enzymes are indicated, the same fragment resulted from digestion with any of the indicated enzymes and HpaII. The broken lines for the normal P3 gene denote partial methylation of the HpaII sites at the $5^{\prime}$ end of this gene. In P3 DNA, fragments were assigned to the normal or translocated gene by the analysis described in Fig. 3 . 

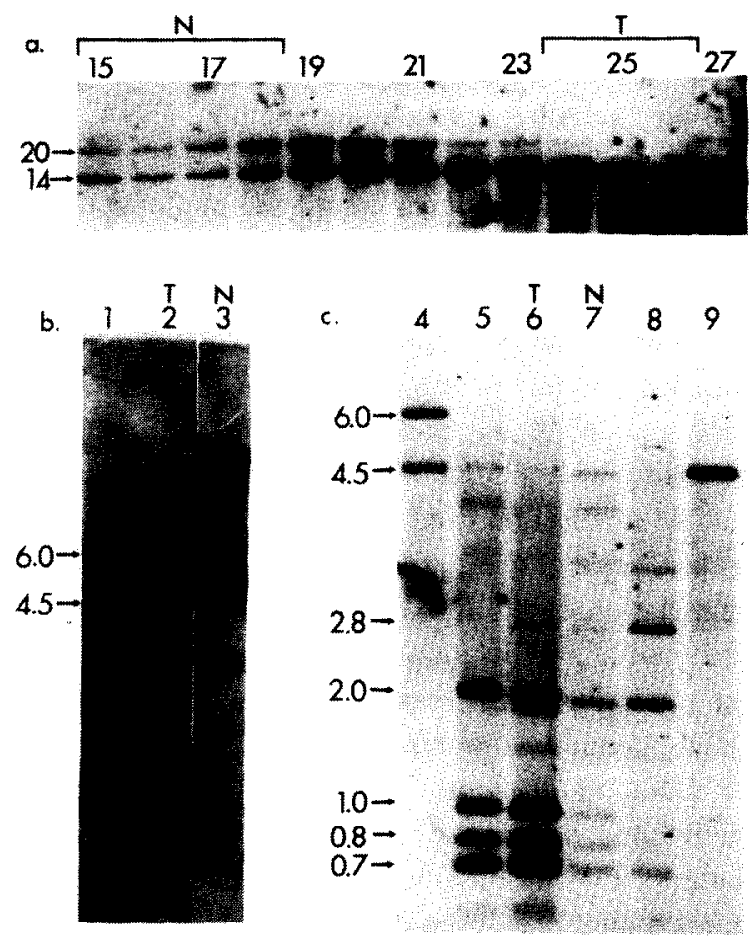

Fig. 3. Methylation of $c-m y c$ in plasmacytoma P3 DNA. (a) High- $M_{\mathrm{r}}$ DNA from P3 cells was digested with $E c o$ RI and fractionated on a sucrose gradient. Fractions 15 to 27 were concentrated by ethanol precipitation, and aliquots were fractionated on an agarose gel. The DNA samples in the gel were blotted onto nitrocellulose by the Southern (1975) procedure and hybridized to radiolabeled c-myc NIARD probe. Fractions 15 to 18, containing the nonrearranged c-myc gene in a $20-\mathrm{kb} E c o \mathrm{RI}$ fragment, were pooled. Fractions 24 to 26 , containing the translocated c-myc gene in a 14-kb Eco RI fragment, were also pooled. (b) DNA samples of P3 DNA (lane 1), fractions 24 to 26 (lane 2), or fractions 15 to 18 (lane 3) were digested with HindIII, fractionated on an agarose gel, blotted onto nitrocellulose paper, and hybridized to the radiolabeled NIARD (see Fig. 2) probe. (c) DNA samples of P3 DNA (lanes 4 and 5), of sucrose gradient fractions 24 to 26 ( $\mathrm{T}$, lane 6 ), of sucrose gradient fractions 15 to 18 (N, lane 7), or of kidney and liver DNA (lanes 8 and 9) were digested with HindIII (lanes 4 and 9) or HindIII + HpaII (lanes $5,6,7$, and 8 ). The digested samples were then fractionated on a $1.1 \%$ agarose gel, blotted onto nitrocellulose paper, and hybridized with the NIARD probe in $6 \times \mathrm{SSC}$ at $68^{\circ} \mathrm{C}$. Sizes of fragments in $\mathrm{kb}$ arc indicated on the left-hand margin of the autoradiographs.

ther digested with HindIII (Fig. 3b). The fraction including the translocated allele contained a large amount of the 6.0-kb HindIII fragment associated with the translocated gene, and a small amount of the 4.5-kb fragment associated with the normal gene (Fig. 3b, lane 2). The fraction including the normal allele was a mixture of about equal amounts of the $6.0-\mathrm{kb}$ translocated fragment and $4.5-\mathrm{kb}$ normal fragment (Fig. 3b, lane 3).

These P3 DNA fractions, along with genomic DNA from $\mathrm{P} 3$ plasmacytoma DNA and a mixture of kidney and liver DN $\Lambda$, were digested with HindIII and HpaII and analyzed by the Southern hybridization procedure (Fig. 3c). The c-myc genes in kidney and liver DNA are found in a (nonrearranged) 4.5-kb HindIII fragment (lane 9) and are methylated to an intermediate extent (lane 8). The c-myc genes in plasmacytoma P3 DNA seem to fall into two sets: one is extensively demethylated, the other extensively methylated (lane 5). The translocated allele appears to be the demethylated c-myc gene, as the fraction including this allele yielded the small fragments associated with extensive demethylation of the gene (Fig. 3c, lane 6). On the other hand, the fraction which included both alleles yielded 4.5and 4.0-kb HindIII-HpaII fragments (lane 7). These larger fragments indicate that the normal allele is extensively methylated, HpaII cutting the HindIII fragment once or not at all. This fraction also yielded a small amount of the $0.7-1.0-\mathrm{kb}$ fragments associated with demethylation. The intensity of hybridization of these small fragments is consistent with the level of contamination by the translocated allele. The hybridization signal of the small fragments (lane 7) is much reduced compared to either the purified translocated fragment (lane 6) or the total genomic DNA (lane 5), even though the hybridization signal of the 4.0 and $4.5-\mathrm{kb}$ fragments is much greater than that for the translocated allele (lane 6) and equal to that for the total plasmacytoma DNA (lane 5). P3 DNA, and DNA from both fractions, yields a $2.0-\mathrm{kb}$ IIindIII-HpaII fragment. From the relative intensity of hybridization of this fragment in the various lanes, it appears that the translocated allele is partially methylated at the HpaII site in the second intron, resulting in a $2.0-\mathrm{kb}$ fragment. Nevertheless, it is also possible that some of this fragment is derived from the population of normal c-myc genes.

At least two HpaII sites at the $5^{\prime}$ end of the c-myc genes in kidney and liver DNA, and in P3 DNA, appeared to be undermethylated. With a 5 '-flanking region probe, we detected a small $(0.6-\mathrm{kb})$ fragment after $\mathrm{HpaII}$ digestion of either $\mathrm{P} 3$ or kidney and liver DNA (Fig. 2, lanes 1 and 2). After digestion with $K p n I$ only, this same probe detected the non- 
rearranged c-myc gene in kidney and liver DNA (lane 4), the nonrearranged gene in P3 DNA (lane 3, 9.8-kb), and the translocated reciprocal product in P3 DNA (lane 3, $11 \mathrm{~kb}$ ). From our limited analysis, we detected hypomethylation of some sites in the $5^{\prime}$ flanking region of the $c-m y c$ gene, but could not distinguish between translocated and normal c-myc genes.

\section{(e) Conclusions}

We have defined three different patterns of methylation for murine $c-m y c$ genes. (i) The translocated c-myc gene in plasmacytoma DNA is largely demethylated and is transcriptionally active. It has been previously shown that the adjoining immunoglobulin gene is also demethylated (Dean et al., 1983). (ii) The nonrearranged gene in plasmacytoma DNA is extensively methylated. In most plasmacytomas, this normal allele is transcriptionally silent (Stanton et al., 1983; Adams et al., 1983). (iii) The c-myc genes in a mixture of kidney and liver DNA are methylated to an intermediate extent; that methylation takes place in the second exon and intron. The transcriptional activity of these normal kidney and liver genes might be very low. Nevertheless, at least in liver DNA, the genes are capable of induction to very high rates of transcription (Makino et al., 1984).

Genes that encode 'housekeeping functions' tend to be undermethylated in their promoter regions, but methylated at their 3' ends (Stein et al., 1983). The kidney and liver c-myc gene seems to be methylated at its $3^{\prime}$ end (Figs. 2 and 3). Our limited analysis suggests undermethylation of the promoter region of the c-myc gene, but more extensive analysis will be necessary to confirm this point.

The murine c-myc gene has more $\mathrm{CpG}$ dinucleotides in its $5^{\prime}$ end than in its $3^{\prime}$ end (CpG dinucleotides are slightly underrepresented in the second and third exons; Stanton et al., 1983; Bernard et al., 1983). Even though the sequence of the second intron is not available, the presence of a single $\mathrm{HpaII}$ site in this intron suggests few $\mathrm{CpG}$ dinucleotides. Thus, c-myc seems to fit the observation of Tykocinski and Max (1984) that eukaryotic genes tend to have many $\mathrm{CpG}$ dinucleotides at their $5^{\prime}$ ends, but few at their $3^{\prime}$ ends. Tykocinski and Max also suggested that $\mathrm{CpG}$ dinucleotides are in low abun- dance in the $3^{\prime}$ end of eukaryotic genes because, in their methylated state, $\mathrm{CpG}$ dinucleotides tend to mutate to $\mathrm{CpA}$ or $\mathrm{TpG}$. The methylation pattern and the $\mathrm{CpG}$ content of the $5^{\prime}$ and $3^{\prime}$ ends of the c-myc gene in kidney and liver DNA are consistent with this hypothesis.

\section{ACKNOWLEDGEMENTS}

We thank Drs. J.L. Claflin, David Friedman, Mary Hummel and Michael Imperiale for commenting on the manuscript, and Emma Williams for assistance in preparing the manuscript for publication. This work was supported by grants No. AI17778 and No. CA39068 from the National Institutes of Health and by a grant from the University of Michigan Biomedical Research Council.

\section{REFERENCES}

Adams, J.M., Gerondakis, S., Webb, E., Corcoran, L.M. and Cory, S.: Cellular myc oncogene is altered by chromosome translocation to an immunoglobulin locus in murine plasmacytomas and is rearranged similarly in human Burkitt lymphomas. Proc. Natl. Acad. Sci. USA 80 (1983) 1982-1986.

Bernard, O., Cory, S., Gerondakis, S., Webb, E. and Adams, J.M.: Sequence of the murine and human cellular myc oncogenes and two modes of $m y c$ transcription resulting from chromosome translocation in B lymphoid tumors. EMBO J. 2 (1983) 2375-2383.

Busslinger, M., Hurst, J. and Flavell, R.A.: DNA methylation and the regulation of globin gene expression. Cell 34 (1983) 197-206.

Compere, S.J. and Palmiter, R.D.: DNA methylation controls the inducibility of the mouse metallothionein-I gene in lymphoid cells. Cell 25 (1981) 233-240.

Cory, S., Gerondakis, S. and Adams, J.M.: Interchromosomal recombination of the cellular oncogene c-myc with the immunoglobulin heavy chain locus in murine plasmacytomas is a reciprocal exchange. EMBO J. 2 (1983) 697-703.

Corcoran, L.M., Cory, S. and Adams, J.M.: Transposition of the immunoglobulin heavy chain enhancer to the myc oncogene in a murine plasmacytoma. Cell 40 (1985) 71-79.

Dean, M., Kent, R.B. and Sonenshein, G.E.: Transcriptional activation of immunoglobulin alpha heavy-chain genes by translocation of the c-myc oncogene. Nature 305 (1983) 443-446.

Dunnick, W., Shell, B.E. and Dery, C.: DNA sequence near the site of reciprocal recombination between a c-mvc oncogene 
and an immunoglobulin switch region. Proc. Natl. Acad. Sci. USA 80 (1983) 7269-7273.

Fradin, A., Manley, J.L. and Prives, C.L.: Methylation of simian virus $40 \mathrm{HpaII}$ site affects late, but not early, viral gene expression. Proc. Natl. Acad. Sci. USA 79 (1982) 5142-5146.

Groudine, M., Eisenman, R. and Weintraub, H.: Chromatin structure of endogenous retroviral genes and activation by an inhibitor of DNA methylation. Nature 292 (1981) 311-317.

Harris, L.J., Lang, R.B. and Marcu, K.B.: Non-immunoglobulinassociated DNA rearrangements in mouse plasmacytomas. Proc. Natl. Acad. Sci. USA 79 (1982) 4175-4179.

Klein, G.: Specific chromosomal translocations and the genesis of B-cell-derived tumors in mice and men. Cell 32 (1983) 311-315.

Makino, P., Hayashi, K., and Sugimura, T.: c-myc transcript is induced in rat liver at a very early stage of regeneration or by cycloheximide treatment. Nature 310 (1984) 697-698.

Messing, J. and Vieira, J.: A new pair of M13 vectors for selecting either DNA strand of double-digested restriction fragments. Gene 19 (1982) 269-276.

Nueberger, M.S. and Cabali, F.: Reciprocal chromosome translocation between c-myc and immunoglobulin $\gamma / 2 \mathrm{~b}$ genes. Nature 305 (1983) 240-243.
Perry, R.P.: Consequences of $m y c$ invasion of immunoglobulin loci: facts and speculation. Cell 33 (1983) 647-649.

Razin, A. and Riggs, A.D.: DNA methylation and gene function. Science 210 (1980) 604-610.

Robertson, M.: Paradox and paradigm: the message and meaning of myc. Nature 306 (1983) 733-735.

Sanger, F., Coulson, A.R., Barrell, B.G., Smith, A.J.H. and Roc, B.A.: Cloning in single-stranded bacteriophage as an aid to rapid DNA sequencing. J. Mol. Biol. 143 (1980) 161-178.

Southern, E.M.: Detection of specific sequences among DNA fragments separated by gel electrophoresis. J. Mol. Biol. 98 (1975) 503-517.

Stanton, L.W., Watt, R. and Marcu, K.B.: Translocation, breakage, and truncated transcripts of c-myc oncogene in murine plasmacytomas. Nature 303 (1983) 401-406.

Stein, R., Sciaky-Gallili, N., Razin, A. and Cedar, H.: Pattern of methylation of two genes coding for housekeeping functions. Proc. Natl. Acad. Sci. USA 80 (1983) 2422-2426.

Tykocinski, M.L. and Max, E.E.: CG dinucleotide clusters in MEC genes and in 5' demethylated genes. Nucl. Acids Res. 12 (1984) 4385-4396.

Communicated by A.R. Riggs. 